\title{
Enterprise Project Driven Teaching Method In Java Web Application Development Based On CDIO
}

\author{
Yin Hong-li \\ The College of Science \\ Qilu University of Technology \\ Jinan, Shandong, P.R.china \\ e-mail:yhl@qlu.edu.cn
}

Keywords: CDIO; Project-Driven; Java Web; Teaching Reform

\begin{abstract}
To handle teaching problems of Java Web application development courses in higher education, the CDIO engineering education methods is used to enhance the practical ability of the undergraduates. In this paper, we focus on enhancing the ability of engineering practice, reform curriculum teaching content and teaching methods. Curriculum teaching content is around the Web project development process by the enterprise project-driven method based on CDIO. It's proved by teaching practice that the reform of curriculum teaching greatly improved the software development capability, teamwork and communication skills.
\end{abstract}

\section{Introduction}

Presently, the studying problems in java web application development is lack of interest and enthusiasm. The students learn passively. In practice, they only imitate the teachers' teaching case which can not improve the software development capability, teamwork and communication skills. However, this course includes extensive knowledge of object-oriented programming, computer network, software engineering, database design, web design, CSS, XML data exchange technology and software system architecture. Therefore, this course requires higher comprehensive ability to the students. Through learning and practicing in the course, students can not only consolidate technical expertise, improve analytical skill and practical ability, but also develop good team spirit.

In this paper, we combine the concept of CDIO teaching methods with the use of enterprise project-driven way to explain the knowledge. Take an online book store as an example, I introduce the CDIO teaching mode of the project at all levels, emphasize "learning by doing", and strengthen the use of knowledge, focusing on the training of the application ability of the students, to meet the market demand for talents

\section{The characteristics and necessity of CDIO method}

\subsection{Characteristics and Enlightenment of CDIO engineering education mode}

The CDIO model as the latest achievements of international engineering education reform in recent years, is " Learning by doing " and "focusing on project teaching and learning" [4]. It is based on the life cycle of the project from the development to the operation. CDIO engineering education model is the latest achievement of international engineering education reform in recent years. The CDIO is an educational framework stressing engineering fundamentals set in the context of conceiving, designing, implementing and operating real-world systems and products. It takes the system development to run the life cycle as the carrier, to let the students to the organic connection between active and practical courses, learning theory, technology and engineering experience. The CDIO model integrates the training objectives into the whole curriculum system, each of which should be implemented in the curriculum and extracurricular activities.

\section{2 shortcomings in teaching of the java web application development course}

Java Web Application Development course is an applied, practical, and skilled course which includes extensive knowledge of object-oriented programming, computer network, software engineering, database design, web design, CSS, XML data exchange technology and software 
system architecture. Web development is a key technology in the field of IT, is the basis of online information application, is an important technical basis of information management, computer science. It is also engaged in the information industry technical staff and managers need to be one of the most important skills to master. The objectives of the course is to enable students to understand the basic principles of web application development, to master a language of web development.

There are some shortcomings in teaching of the course.

A. Curriculum content is not reasonable

On the teaching situation of Java Web in university, curriculum setting and teaching mode is still the traditional content and does not follow the development trend of modern technology. The teaching materials in Java Web courses are based on the knowledge and skill training which cannot meet the demand of enterprise [1]. Students although studied java for programming, they just mastered the base skill in programming. Because there are lack of comprehensive experiments in teaching's plan, students lack of capacity of comprehensive practical and flexible application. The programming capabilities of students is directly related to the implementation of our teaching. We select java language for programming as a programming language in teaching.

$\mathrm{B}$. Teaching mode is single

Although in the past teaching method we have adopted the task driven method, the knowledge in the project targeted is not strong, every task is only for a small part of the knowledge. Although in the past teaching with task driven teaching approach, but the knowledge in the project targeted is not strong, every project is only for a small part of the knowledge, the teaching mode is single. These traditional teaching methods cannot guide the students to focus on some scattered knowledge, but let the students be trivial knowledge and application in the development of the system. In addition, On teaching the theory, we use the courseware teaching of "preaching"; on Experimental teaching, students complete experiments in the teacher's prompts ; and on assessment methods, the tests are subject to confirmatory and lack of comprehensive [3]. Thus, Students focus only on theoretical knowledge as well as on-machine verification process, and neglects the comprehensive practical ability, eventually leading to the programming capabilities of students is not improved.

C. Lack of engineering capability

Though students do some exercises through experiments and operating the programming, and they can also program to solve some small problems, such as scheduling problem, the use of validation controls, the use of the database control, students are lack of complete training and a certain scale system development [5].

\section{Teaching reform in java Web development curriculum based on CDIO}

Aiming at the drawbacks of traditional Web development course and CDIO technology teaching in the curriculum teaching idea, we developed Web technology teaching, combined with the CDIO teaching philosophy of practice and exploration, and achieved good teaching effect.

\subsection{Comparison between CDIO and traditional teaching mode.}

The biggest difference between CDIO and traditional teaching mode is mainly reflected in the process of teaching and learning, as well as the way of learning experience and skills training methods. Therefore, the traditional concept of education, which aims at imparting knowledge, is transformed into "taking students as the center" [4]. The students change from the passive knowledge receivers to the active ones, and the teachers change from the knowledge learners to the leaders and promoters. Let the students learn the professional knowledge from the perspective of solving engineering problems, master the engineering thinking method, and improve the ability of independent analysis, understanding and solving problems [7].

\subsection{The basic idea of the introduction of CDIO in the course}

Taking the actual project as the background, the project implementation as the main line runs through the whole process of teaching, the specific ideas are shown in Figure 1. The basic idea of combining CDIO teaching theory, fully embodies the concept of teacher as leader and students as main body. 


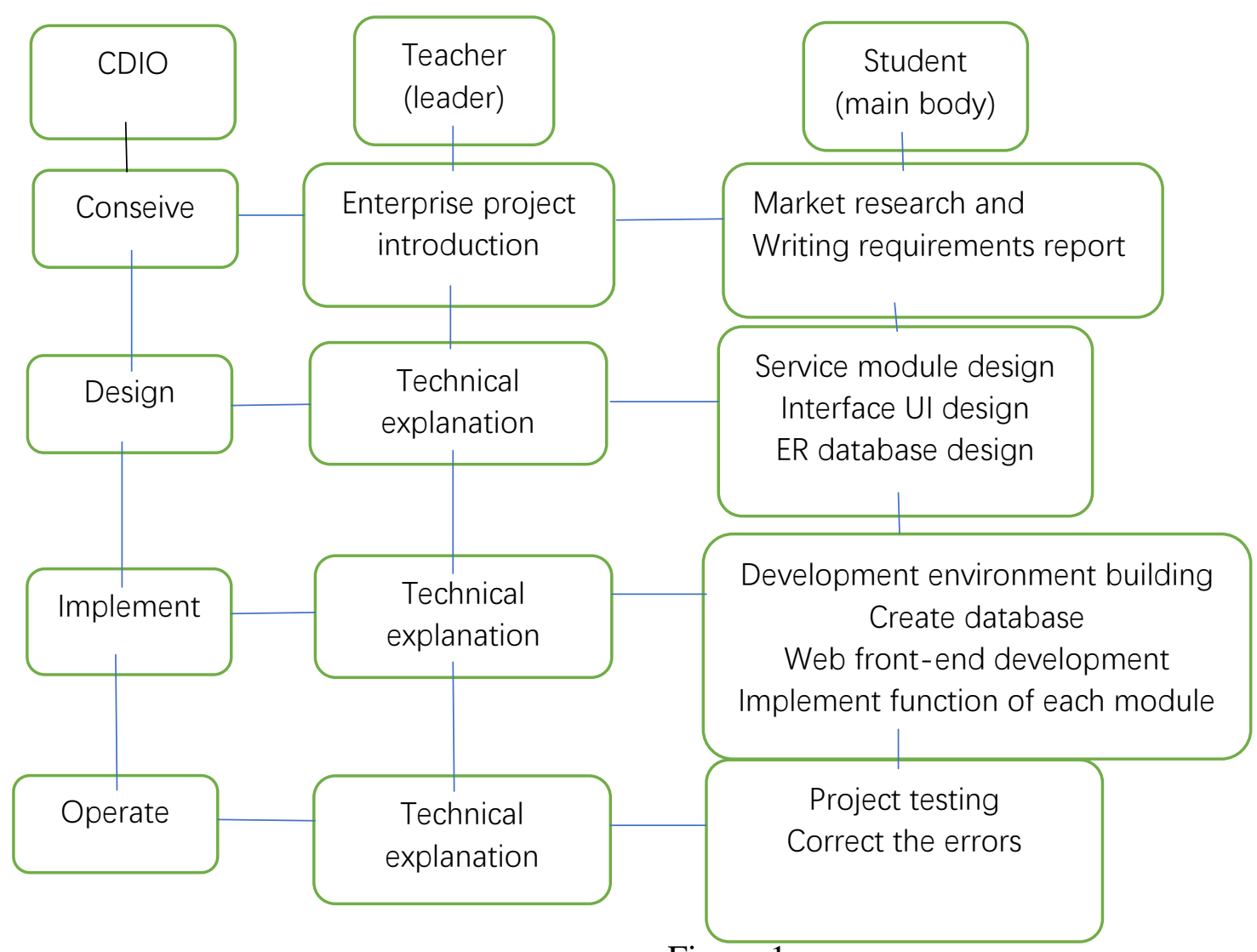

Figure 1

\subsubsection{Conceive}

In the design stage, teacher introduce the enterprise project. According to the software engineering design idea of web application system, teacher explains the basic process and development of web application systems (such as online bookstore system) and make students have an overall understanding of the project[2]. The teacher assigned the team leader,and a team is composed of 3-4 students. under the leadership of the leader, The students launch the demand analysis to the project, study the project implementation plan, and carry on the assignment to the member of team.

Take online bookstore system as an example, the system is divided into front management and background book and order management, as shown in figure 2 . 


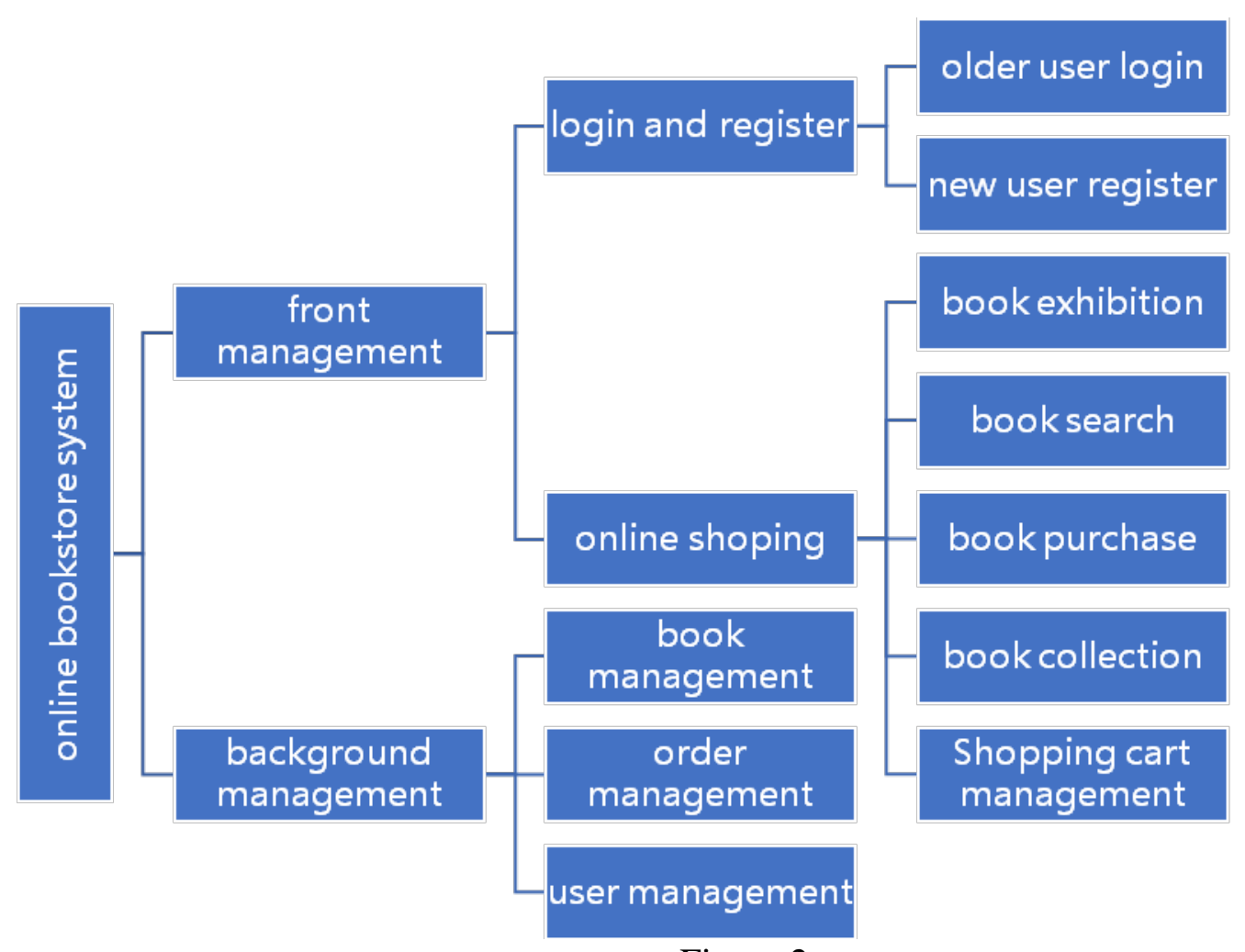

\subsubsection{Design}

Figure 2

In the design stage, through the application of the function of the system design, the teacher guides the students to design the corresponding functional modules, ER database model and UI interface. In the design stage, we should fully consider the feasibility of functional modules, including technical feasibility, functional feasibility and legal feasibility.

\subsection{3 implement}

In the implementation stage, teachers demonstrate the implementation of the typical functional modules, such as data table creation, the realization of the program, art picture making. According to the teacher's reasoning, the students achieve a number of functional modules. In the process of implemention, the teacher answer the questions of studentss. Team members support each other, discuss, learn to think and listen to the views of others, learn to communicate and solve problems, cultivate the team's overall sense of responsibility.

\subsubsection{Operate}

Project testing includes functional testing, interface testing, document testing. System function and performance which are listed in the system requirements all need to be tested and and need to correct the errors found during the testing.

\section{Conclusion}

This paper presents a method of enterprise project-driven teaching method based no CDIO engineering education model. The method takes CDIO as the core guiding ideology, takes active project driven learning as the main means, and has certain scientific and advanced nature. According to the enterprise project, this paper establishes the course content by the CDIO engineering education model. On the one hand, it guides the direction of teachers' teaching, and gives clear boundaries for the completion of teaching objectives. The active project driven teaching mode has changed the situation of passive acceptance by the students in the past, established the dominant position of the students, mobilized the enthusiasm of the students, and promoted the students' ability of self-study. The goal of course reforming is to improve the teaching quality. As a result, we can achieve the goal of bringing up students to talents when every student can grasp professional skills completely. It is effective that we reform the course of java web application development through using the theory of CDIO [6]. 


\section{Reference}

[1]Yan J J, Ma Y F. Learning-Sphere Curriculum and Course Development of" Java Web Application Development" Based on Working Process[C]//Applied Mechanics and Materials. Trans Tech Publications, 2013, 321: 2956-2959.

[2]Edström K, Kolmos A. PBL and CDIO: complementary models for engineering education development[J]. European Journal of Engineering Education, 2014, 39(5): 539-555.

[3]Sayrol E, Bragós R, Alarcón E, et al. Mixed Integration of CDIO skills into Telecommunication Engineering Curricula[J]. Elektronika ir Elektrotechnika, 2015, 102(6): 127-130.

[4]Yang Z, Shen Q. Constructing Practical Teaching System of International Trade Major Based on CDIO Engineering Education Concept[C]//2015 International Conference on Social Science and Higher Education. Atlantis Press, 2015.

[5]Yan $\mathrm{H}, \mathrm{Hu} \mathrm{H}$. Research and realization of ISIC-CDIO teaching experimental system based on RFID technology of web of things[J]. Journal of Bionanoscience, 2013, 7(6): 696-702.

[6]Chunying L, Zhikang T. Practice of software engineering course design based on CDIO mode [J][J]. Experimental Technology and Management, 2011, 6: p173-174,178.

[7]Wang Y, Sun J, Wang S. Operation and Management of Urban Rail Transit Education Reform Based on CDIO[M]//ICTE 2015. 2015: 3097-3104. 